\section{Una perspectiva ética en el quehacer médico}

\author{
Francisco Gutiérrez \\ Sánchez ${ }^{*}$
}

\section{RESUMEN}

Este artículo trata sobre las responsabilidades y los valores éticos del médico y del todo el personal de salud involucrado en la praxis médica en general. Hace énfasis en el análisis de las virtudes y valores fundamentales de la acción o del acto médico en consecuencia con los derechos y los deberes tanto del trabajador de la salud como del paciente. Por último, bajo la perspectiva ética se estudian casos sobre las enfermedades infecciosas y la ética médica.

\section{PALABRAS CLAVE}

Ética. Ética Médica. Bioética. Filosofía Moral Médica.

* Licenciado en Filosofía por la Universidad de Costa Rica. Profesor de Ética de la Escuela de Filosofía, UCR y Coordinador de la Cátedra de Pedagogía de la UNED.

Rec. 14-11-05 Acep. 28-0 3-06

\section{Abstract}

This article is about responsibilities and ethical values of physicians and health personnel involved in the medical practice in general. It emphasizes on the analysis of virtues and fundamental values of the medical act and, consequently, on the rights and duties of health workers and patients. Finally, some cases of infectious illnesses and medical ethics are studied under the ethical perspective.

\section{Keywords}

Ethics, Medical Ethics, Bioethics, MedicalMoral Philosophy

\section{Valores éticos presentes en el quehacer médico}

\section{Ética y los servicios médicos}

Los servicios médicos $\mathrm{y}$, en general los de la salud, pueden considerarse como bienes de mérito muy importantes e indispensables para la sociedad; es por ello que es importante que la educación médica actualice sus contenidos, tanto técnicos como éticos, para que los profesionales no corran el riesgo de mala praxis y que surja en el médico una conciencia que enfrente diariamente dilemas de tipo ético en el ejercicio de la práctica médica. La Revista Bioetica, de la Oficina Panamericana de la Salud (1985:101), nos dice que: 
El estudio del hombre constituye, entonces, la base de una educación completa $\mathrm{y}$ del conocimiento de una normativa bien delineada basada en patrones éticos fundamentales y universales, dada esa común dignidad de naturaleza propia de cada hombre y de todos los hombres. Este estudio ha de estar presente no solo en los programas básicos de los profesionales de salud, sino también en la educación continua, con el fin de formar a profesionales idóneos capaces de enfrentar con responsabilidad el ejercicio profesional y de ayudar a otros, de tal modo que su ayuda sea un acto que dignifique a la persona".

El profesional de la salud deberá atender los planteamientos éticos que lleven a cuestionar la existencia de determinadas acciones donde incurra, con el objeto de proporcionar un paradigma básico en la toma de decisiones conflictivas que lo obliguen a establecer juicios de valor, eligiendo un camino que respeta las esperanzas y los deseos del paciente.

Los principios éticos inspiradores de las relaciones profesionales entre los trabajadores de la salud, las instituciones y pacientes de este sector, son de trascendental importancia y de gran significancia para la formación de la conciencia informada, tanto del médico como del paciente; esto hace que se rompa o disminuya cada vez más la idea de que el médico es la única autoridad e inapelable absoluta y que la opinión o deseos del paciente son insignificantes o de poca relevancia.

Es aquí en donde surge el respeto y la consideración que se debe tener al otro y para consigo mismo, para establecer una mayor y mejor comunicación en las relaciones profesionales médico-pacientes, y por supuesto, forjar la conciencia de ambas partes.

a) Ética médica

¿Cuál es el deber ser del médico?, o en forma más precisa, ¿Cuál debe ser el perfil ideal del profesional en salud en el mundo actual?

Sin duda alguna, son preguntas bastante complejas de contestar, pues deben tomarse en cuenta varios aspectos que se enumerarán a continuación:

1. La preparación científica o profesional que el individuo debe tener o adquirir por 
medio del estudio concienzudo acerca de las diferentes y variadas ramas que ofrece el campo de la salud.

Es preponderante que se conozca a fondo lo básico de la profesión, para así poder tratar y resolver la dolencia que el paciente exprese, sin duda alguna, una preparación científica adecuada es importante para brindar una atención integral y de calidad. Deberá mantenerse informado acerca de nuevas enfermedades, nuevas técnicas y materiales para ofrecer lo mejor de sí, en el trabajo con los pacientes.

2. Otro aspecto de suma importancia es el humanístico o ético-moral. Entre los elementos de este aspecto están la honradez, honestidad, perseverancia, prudencia, responsabilidad, valentía $y$ todo lo que exprese el amor por el prójimo, el amor por la profesión; en fin, el amor a la vida.

Además, el profesional en salud debe ser generoso, leal, sencillo y sincero, respetuoso con el paciente $\mathrm{y}$ debe poseer capacidad de entrega, cualidades básicas e indispensables de todo el que aspire a ser médico $y$, en general, el profesional de la salud, como lo indica Polaino:

La actual medicina despersonalizada puede haber olvidado por considerarlo como una cuestión obsoleta el tema de la amistad y del respeto entre el médico y el paciente. En esas circunstancias puede predecirse para ella un desastroso futuro. Este olvido manifiesta de forma explícita que se está considerando al paciente como lo que no es. Cualquier médico sabe que cada uno de los pacientes tiene derecho a no ser considerado por ningún ser humano como un nadie, y si realmente el médico es una persona humana, si el médico es importante para si mismo, logicamente comprenderá que al tratar al paciente como a un nadie, inevitablemente él mismo se trata asimismo, en ese mismo acto, como otro nadie. La pérdida del respeto al paciente implica de forma irrenunciable la pérdida del respecto a si mismo (Polaíno, 1987:249).

¿Pero qué sucede cuando el médico es negligente, indolente, apático, asiste a su trabajo solo por 
cumplir, sin importarle las características o demás rasgos personales o sociales de la población por atender y que demuestre un claro desinterés por conocer las necesidades de sus pacientes, casi que atiende solo por salir del paso? En este caso, se está ante un profesional que no cumple con el juramento ético-profesional, $y$ concurrirá a su trabajo a realizar el menor esfuerzo, no efectuará diagnósticos consistentes, ni tratamientos curativos eficaces. La dedicación profesional es una mística que siempre debe estar presente en todas las oportunidades laborales, ya sea en las consultas privadas o en cualquier forma de consulta institucional.

Las actividades profesionales médicas requieren de un tipo de persona con gran sensibilidad social, que esté dispuesto a brindar todo su apoyo profesional acompañado de cordialidad y cariño, paciencia, prudencia y alegría, atributos muy importantes en un profesional que debe ayudar a sus semejantes con sabiduría y habilidad. Piwonka al respecto nos dice:

En el ejercicio profesional se presentan situaciones conflictivas que, junto a una formación profunda y un cono- cimiento del hombre acorde con su naturaleza espiritual y trascendente, demandan una actitud de servicio empática, es decir, la disposición arraigada de ayudar al otro, en la que confluyen el intelecto, la afectividad $y$ el hacer. Estos aspectos pueden englobarse, con propiedad bajo el concepto de sabiduría. La sabiduría en el orden natural se identifica con la filosofía, el saber ordenado por excelencia, precisamente porque trata de los últimos principios que constituyen el fundamento de la realidad $y$, sobre todo, los fines de la vida humana. Si nos sentimos desorientados y dispersos es porque falta un conocimiento más universal y profundo, en el que se integran los saberes más especializados: un saber comprensivo y radical que nos permitirá junto con el avance tecnológico no olvidar que la dignidad del hombre no está precisamente en ese avance sino en el hombre mismo (Piwonka, 1984:89).

El profesional en salud debe encarar las demandas poblacionales con responsabilidad, con principios éticos arraigados en el ser- 
vicio humano incondicional, pero también debe saber aprovecharse de estas cualidades para rediseñar procesos preventivos y educativos en salud, y así alcanzar una mayor calidad del servicio médico y honorabilidad de la profesión.

"La mejor política es la honradez" escribió el gran filósofo Enmanuel Kant, premisa válida hasta nuestros días y que debe iluminar todo el quehacer médico.

b) EL SIDA y la ética médica

El síndrome de inmuno-deficiencia adquirida (SIDA) hizo su aparición hace poco más de veinte años. Desde entonces, millones de personas que han adquirido este mortal virus se han visto discriminados por algunos sectores de la sociedad, sin importar si los enfermos son niños o adultos que fueron infectados accidentalmente por medio de transfusiones sanguíneas. Bayer lo analiza de esta manera:

En los Estados Unidos, alrededor de una cuarta parte de la población cree que la gente con dicha infección debe ser excluida de las escuelas, centros de trabajo y otros lugares públicos. Uno de cada cuatro también piensa que las personas que sufren trastornos relacionados con el VIH no deben ser tratados con compasión.

Estas observaciones son comunes en muchas regiones del mundo. Los temores y antipatía a menudo están fomentados por una hostilidad visceral hacia los grupos popularmente vinculados al SIDA: los homosexuales, los drogadictos y las prostitutas. La discriminación de las personas infectadas por VIH no solo es objetable por razones morales, sino que puede ser contraproducente por motivos de salud pública" (Bayer, 1984:192).

Al ser el VIH un virus mortal, muchos profesionales en salud se encuentran con el dilema de recibir o no a los pacientes que solicitan atención en los consultorios, en estos casos, la educación acerca de la enfermedad continúa siendo la mejor respuesta. Debe haber educación en los siguientes sentidos:

1. Todo profesional en las ciencias de la salud debe actuar responsablemente, para no contagiarse ni ser vehículo de transmisión a otras personas. 
2. El carácter ético de maximizar los esfuerzos y cuidados de tratamiento para detener toda infección.

3. Cada tratamiento exige los mejores métodos de esterilización de equipos y materiales.

4. Debe contarse con todos los recursos y avances tecnológicos utilizables para efectuar su labor de manera segura, que guarde su salud y la de sus pacientes.

En resumen, cualquier trabajador de la salud debe contar, para hacer frente a la enfermedad, con una asepsia, protección, esterilización y desinfección que le den seguridad y libertad para trabajar con esta clase de enfermos, ya que, de lo contrario, sería una actitud negligente. Pero el sentido profesional más importante en la atención del enfermo con SIDA es el ético, en donde la salud del paciente debe estar en primerísimo lugar, puesto que debe ser tratado como un ser humano con dignidad, el cual necesita alivio, afecto y consuelo. El paciente no es un objeto, sino un sujeto con derechos y deberes.

El personal de salud debe adquirir responsabilidades, obligaciones y deberes hacia todas las per- sonas que soliciten los servicios; por ello, cabe señalar que no es ético negar a un paciente un tratamiento solamente por encontrarse infectado con el virus del SIDA. Ríos y Álvarez se expresan de la siguiente manera:

La discriminación por una enfermedad infecciosa puede ser tan injusta como la motivada por otras razones moralmente irrelevantes como la raza, el sexo o una discapacidad. Por otro lado, es moralmente inaceptable negar ciertos derechos, beneficios o privilegios cuando los riesgos para la salud son solo teóricos o muy escasos y cuando el desempeño del médico es adecuado (Ríos y Álvarez, 1988:93).

El atender o no pacientes con SIDA no debería ni cuestionar, en tanto que se debe utilizar con todos los pacientes, sin excepción alguna, las medidas adecuadas de protección y de seguridad, extremando las medidas de protección e higiene, con lo que se garantiza el bienestar, tanto de los pacientes como del médico. Al respecto, Polaino nos dice lo siguiente:

El problema del SIDA y la ética médica y la que tiene que ver con los demás profe- 
sionales de la salud también ha sido motivo de conferencias y foros. Siempre se ha llegado a la conclusión de que, desde el punto de vista ético, las personas que padecen la enfermedad no pueden ser abandonadas $\mathrm{o}$ relegadas por aquellos que tienen la obligación de cuidarlas, solo por el temor de que puedan contagiarse. (Polaino, 1987:240).

Para finalizar, debe decirse que la actitud más ética a la que el médico y su personal están llamados a realizar, con respecto a las enfermedades contagiosas, es la de prevenir su diseminación y colaborar de lleno en las campañas de prevención y educación sobre estos temas dirigidos a toda la población en general.

¿Qué moral o ética profesional puede existir, si en lugar de colaborar para disminuir en parte el sufrimiento de una persona que lucha contra la muerte, se contribuye a destruir su vida aún más, negándole la atención necesaria?

El personal de salud tratará de contestar a esta pregunta, tomando en cuenta la conciencia y los valores que le hayan inculcado en las escuelas de medicina $u$ otras dependencias e instituciones que tienen relación directa con la salud, de ahí la gran importancia y responsabilidad de estar al día en estos temas.

\section{BIBLIOGRAFÍA}

Bayer, R. (1984), Aspectos Legales y éticos relativos al SIDA. Puerto Rico. Editorial de la OPS

Berlinguer.G. (1994), Ética, Salud, y Medicina. Montevideo. Editorial Nordan.

Bermejo J. Francisco (2004), Ética y Trabajo Social. Madrid. Editorial Universidad Pontificia Comillas.

Drane, J. (1978), Gobierno y Bioética, Tomo I SMU. Montevideo. Editorial Nordan.

González, Jaime (2000), Prolegómenos para una ética profesional. Heredia. Editorial EUNA.

Hipócrates (2001), Tratados Médicos. Barcelona Anthopos Editorial.

Oficina Panamericana de la Salud (1985), Revista de Bioética. Puerto Rico.

Maliandi, R. (2004), Ética: Conceptos y problemas. Buenos Aires. Editorial Biblos.

Piwoka, A. (1983), Saber bien para hacer bien. Puerto Rico. Editorial de la OPS.

Polaino, F. (1987), Tratado general de Bioética. Madrid. Editorial EUNSA.

Portillo, J. (1999), Ética y Salud. Barcelona. Editorial Paidos.

Río y Álvarez. (1988), Ética, Salud y Enfermedad. Madrid. Editorial M.SC. 


\section{ESPIGA}

Rivera, E. (2001), Ética y Trasplantes de órganos. México. Fondo de Cultura Económica.

Sanabria, R. (1964), Ética. Madrid. Editorial Paidos.

Sánchez, A. (1980), Ética. México. Editorial Grijalbo. 